\title{
Predictors of quality of life improvement following peer mentoring in African- American women with systemic lupus erythematosus (sle)
}

\begin{abstract}
Background: Systemic lupus erythematosus is a complex autoimmune disorder with heterogeneous presentation. Behavioral interventions have had mixed effects among this population, particularly among African American women, whom are disproportionately affected. The present study investigates predictors of individual responsiveness to a peer mentoring program designed to provide modeling and reinforcement by peers to African American women with systemic lupus erythematosus.
\end{abstract}

Methods and findings: Potential predictors of outcome in the analyses include sociodemographic variables, psychosocial variables, and self-reported disease symptoms. Changes in patient reported outcomes were calculated between pre- and post-intervention time points. To categorize patients into groups based on level of improvement, a cluster analysis using the Ward's Minimum Variance method was performed. Statistical comparisons of groups for demographics and patient reported outcomes were performed using Fisher's exact test or Wilcoxon rank-sum tests. Two disease activity variables significantly predicted individual improvement, whereas other factors assessed had no statistically significant effect. Those mentees with worse self-reported baseline symptom severity (SLAQ2) and disease activity ratings (SLAQ3) had the highest likelihood of improvement.

Conclusion: While other factors may influence individual response to the intervention, this analysis stems from a pilot study and may be underpowered to detect them. This subject warrants further study to determine the characteristics of individuals more or less likely to benefit from an intervention so that it can be tailored to their needs. The present data show that individuals with the most severe and active disease may benefit more from an intervention providing social support and targeting their selfmanagement practices.

Keywords: peer mentoring $•$ systemic lupus erythematosus $\bullet$ prediction $\bullet$ individual change $\bullet$ quality of life • African American • women and mortality rates are among African American women [1,2]. SLE affects approximately 1 in 250 African American women of childbearing age, and African Americans overall have three to four times greater prevalence of lupus, risk of developing lupus at an earlier age, and lupus-related disease activity, damage, and mortality compared with Caucasians [3-8]. Both the condition itself and its treatment can cause deficits. Symptoms, side effects, and complications can lead to significant functional and emotional challenges [9]. Patients often experience a high degree of psychological symptoms, including anxiety, depression, mood disorders, and decreased health-related quality of life [10-16]. Deficits in patients with less active SLE are usually not severe, but they can have a substantial impact on daily life [17]. Moreover,
Edith M Williams*1, J. Madison Hyer', Ramakrishnan Viswanathan' ', Trevor D. Faith', Jim C. Oates ${ }^{2,3}$ \& Leonard Egede ${ }^{4}$ 'Department of Public Health Sciences, Medical University of South Carolina, USA

2Division of Rheumatology and Immunology, Medical University of South Carolina, USA

${ }^{3}$ Rheumatology Section, Ralph H. Johnson VA Medical Center, USA

${ }^{4}$ Department of Medicine, Medical College of Wisconsin, USA

*Author for correspondence: wiled@musc.edu

\section{Introduction}

Patients with systemic lupus erythematosus (SLE), the most common and diverse type of lupus, may experience deficits in quality of life, including alertness, behavior, recreation/ pastime, sleep and rest, home management, social interaction, and emotional balance. In the United States, the highest lupus morbidity 
subjective quality of life symptoms are among the most common problems reported by patients with SLE [17].

In a recent study (Williams et al.,) we reported the results of a pilot study of peer mentoring in 33 African American women with SLE, in which positive effects were observed. In particular, mentees showed trends toward lower disease activity, higher quality of life, lower pain symptoms and higher social support (effect sizes $>0.3$ ) following participation in the intervention. In addition, both mentees and mentors gave very high scores for perceived treatment credibility and service delivery [18].

Since group results can mask the variability in individual responses to behavioral intervention, it is of interest to further investigate the specific patient factors that are associated with a more (or less) positive outcome.

Participation in a peer mentoring program can be quite time-consuming and a serious commitment for patients. Identification of specific patient characteristics that are associated with a positive response to peer mentoring could allow us to reassure patients who possess these characteristics that participating in this type of intervention is almost certainly worth the effort. Conversely, if we are able to identify patients who are less likely to benefit from peer mentoring, we may advise them accordingly and explore other treatment options. Perhaps more importantly, we can use the knowledge gained to adapt peer mentoring programs to yield optimal benefit for a larger percentage of the target population.

Sociodemographic (e.g., age, sex, and education), clinical (e.g., disease-related damage), subjective (e.g., self-reported SLE symptoms), and/or psychosocial (e.g., social support, health literacy, stress, trust, patient-centered care, perceived control, spirituality, and discrimination) factors may play a role in predicting the outcome of peer mentoring. From a practical point of view, it would be desirable to be able to identify patients who are most likely to respond to peer mentoring on the basis of information that can be collected with relatively little effort (e.g., sociodemographics, basic clinical data). However, use of other patient-reported outcomes (e.g., SLE symptoms) and performance indicators (health literacy and self-efficacy test results) may also provide useful in maximizing such predictions.

The present study investigated the potential predictors of individual responsiveness to a peer mentoring program that was designed to provide modeling and reinforcement by peers to other African American women with lupus (mentees) to encourage mentees to engage in activities that promote the learning of disease self-management skills and support the mentees' practice of these learned skills. We examined the association between health-related quality of life, self-management, and self-reported disease activity improvement with socio-demographic and psychosocial variables and self-reported disease symptoms.

\section{Patients and Methods}

Study sample and design

For a detailed description of the pilot peer mentoring program, the reader is referred to Williams [18]. Briefly, 33 African American women with SLE, participating in a webbased lupus database project at an academic medical institution, were invited to participate in a novel peer mentoring program to improve disease self-management. Those who expressed potential interest in participating in the program completed a screening interview that included a measure of lupus self-efficacy [19]. Patients who scored less than 7 points on the $0-10$ point scale were considered eligible to participate as a mentee. This eligibility criterion was used to identify patients who would both be motivated to participate in the program, and would potentially benefit from its content. Patients who scored 7 or more points on the $0-10$ point scale were invited to serve as peer mentors.

Eligible patients were assigned to the mentor group $(n=10)$ or to the mentee group $(n=23)$. To evaluate the effect of the peer mentoring program, the self-reported questionnaires administered at baseline were repeated at mid-intervention and directly following peer mentoring. The pilot project was approved by the institutional review board at the Medical University of South Carolina (Approval number: Pro00050703), abided to the Helsinki Declaration, and all patients provided written informed consent prior to study participation.

The peer approaches to lupus selfmanagement (PALS) peer mentoring program

The peer mentoring program consisted of twelve weeks of peer mentoring that included one standard educational session by telephone for approximately 60 minutes every week [18]. The weekly educational sessions were 
generally structured in three parts: introduction, structured education, and problem solving. The intervention incorporated both support and structured self-management education. For the support component of the program, mentors and mentees were able to discuss their own experiences and potential solutions, based on the patient's needs. For example, the mentor could begin each session by asking for updates on how the mentee has been progressing with SLE symptoms and then move on to the scheduled agenda for the week. Throughout the session, the mentor would give personal anecdotes regarding how the content related to both her life and the mentee's day-to-day SLE experience. The mentor would then conclude the session by asking the mentee if she has questions about the material and giving advice on how to incorporate the information into her own life. The structured self-management education consisted of weekly content adapted from the modules of the Chronic Disease Self-Management Program (CDMP), Arthritis Self-Management Program (ASMP), and Systemic Lupus Erythematosus Self-Help (SLESH) Course [20], and further tailored to African American women with six added sessions based on cultural issues reported as important to African Americans in earlier research conducted by the principle investigator $[21,22]$. These sessions addressed goal setting/ action planning, exercise, medications, effective communication, nutrition/healthy eating, stress relaxation techniques, coping, body image, complications, self-monitoring, sexuality/sexual health, and trust.

\section{Primary results}

For a detailed description of the pilot project results, the reader is referred to Williams [18]. To summarize, at mid-intervention (6 weeks from baseline), mentees showed a trend toward lower disease activity, higher quality of life, lower pain symptoms and higher social support. At post-intervention, we observed statistically significant decreases in patient-reported disease activity as measured by the Systemic Lupus Activity Questionnaire ((SLAQ) significant change score of 24.70 or $25 \%$ change in patient global assessment of overall lupus disease activity, $\mathrm{p}<0.001$ ), incrementally improving trends in patient activation, and statistically significant decreases in depression (significant change score of 2.62 or $11 \%$ change in Personal Health Qquestionnaire-8 score, $\mathrm{p}=0.05$ ) and anxiety (significant change score of 3.52 or $15 \%$ change in Generalized Anxiety Disorder-8 score, $\mathrm{p}=0.018)$. In addition, both mentees and mentors gave very high scores for perceived treatment credibility and service delivery [18].

\section{Study measures}

The self-report measures of health-related quality of life, self-management, and disease activity that were used in this report are summarized in Table 1.

\section{Outcome measures}

For the current analyses, measures of disease activity, depression, anxiety, quality of life, and social support, for which statistically significant differences were observed at post-intervention [18] (see primary, secondary, and covariate measures in Table 1), were selected for further investigation.

\section{Predictors}

Potential predictors of outcome variation that were included in the analyses were: sociodemographic and psychosocial variables, and self-reported disease symptoms.

\section{Statistical methods}

Descriptive statistics are presented as frequencies (percentages) for patient demographics and as median (inter-quartile range) for patient reported outcomes (PROs). Overall changes in PROs were calculated between pre- and postintervention time points, not considering the mid-point. To categorize patients into groups based on level of improvement, a cluster analysis using the Ward's Minimum Variance method was performed. Patient reported outcomes selected to define the clusters were identified in a previous study [18] as having an effect size of $\geq$ 0.20 [23,24], although small, we consider them to be meaningful changes in this exploratory study. Statistical comparisons of groups for demographics and PROs were performed using Fisher's exact test and Wilcoxon rank-sum tests respectively. Statistical significance was assessed at $\alpha=0.05$. No corrections for multiple comparisons were performed since this is an exploratory study. All analyses were performed using SASC software version 9.4 .

\section{Results}

At baseline, information from 23 subjects was available of whom three did not have followup measures. Results of the statistical analyses presented here are based on the 20 subjects who had both measurements. (Information including 3 subjects not included in the analysis is presented in [18]. Characteristics of the 


\begin{tabular}{|c|c|c|}
\hline \multicolumn{3}{|c|}{ Primary Outcomes Measures } \\
\hline LUP-QOL $[1,2]$ & $\begin{array}{l}\text { Lupus Quality of Life assessment incorporates the Medical Outcomes } \\
\text { Study Short Form } 36 \text { Health Survey and the Functional Assessment of } \\
\text { Chronic Illness Therapy and Fatigue } \\
\text { Scoring Range: 0-100 with } 100 \text { indicating best HRQOL }\end{array}$ & $\begin{array}{l}\text { f Health-related quality of life measure } \\
\text { specific to lupus }\end{array}$ \\
\hline PAM $[3,4]$ & $\begin{array}{l}\text { Patient Activation Measure } \\
\text { Scoring Range: } 0-100 \text { with } 100 \text { being the 'most activated' }\end{array}$ & $\begin{array}{l}\text { Assesses an individual's knowledge, skill, } \\
\text { and confidence for managing their health } \\
\text { and healthcare }\end{array}$ \\
\hline \multicolumn{3}{|c|}{ Secondary Outcomes and Process Measures } \\
\hline SLAQ [5] & $\begin{array}{l}\text { Systemic Lupus Activity Questionnaire } \\
\text { Scoring Range: 0-33 with } 33 \text { indicating the most activity }\end{array}$ & $\begin{array}{l}\text { Disease activity, prevalence, and severity of } \\
\text { symptoms in the previous month }\end{array}$ \\
\hline $\begin{array}{c}\text { Treatment credibility } \\
\text { scale developed by } \\
\text { Borkovec and Nau } \\
\text { (1972) [6] }\end{array}$ & $\begin{array}{l}\text { Modified questionnaire with four 10-point Likert scales } \\
\text { Scoring Range: } 10-40 \text { with } 40 \text { indicating highest credibility }\end{array}$ & $\begin{array}{l}\text { Assess differences in outcome expectancy. } \\
\text { Asks how logical the treatment seems, } \\
\text { how confident participants are about } \\
\text { treatment, and their expectancy of success }\end{array}$ \\
\hline General Scale & $\begin{array}{l}\text { Previously validated general scale, } 2 \text {-item 5-point Likert scale } \\
\text { Scoring Range: 2-10 with } 10 \text { indicating highest satisfaction }\end{array}$ & Satisfaction with care \\
\hline \multicolumn{3}{|c|}{ Covariates } \\
\hline NHIS & $\begin{array}{l}2002 \text { National Health Interview Survey } \\
\text { Captures age, marital status, education, household income, and } \\
\text { health insurance status }\end{array}$ & Demographics \\
\hline CHLSS [7] & $\begin{array}{l}\text { Chew Health Literacy Screening } \\
\text { Scoring Range: 0-12 with } 12 \text { indicating the highest literacy }\end{array}$ & $\begin{array}{l}\text { Assesses health literacy- the patient's } \\
\text { ability to obtain and understand health } \\
\text { information }\end{array}$ \\
\hline BILD [8] & $\begin{array}{l}\text { Brief Index of Lupus Damage } \\
\text { Scoring range: 0-10 with } 10 \text { indicating greatest damage }\end{array}$ & $\begin{array}{l}\text { Designed to quantify cumulative organ } \\
\text { damage due to SLE }\end{array}$ \\
\hline $\begin{array}{l}\text { Arthritis Self-Efficacy } \\
\text { Scale [9] }\end{array}$ & $\begin{array}{l}\text { Pain and other symptom subscales reworded to reflect lupus rather } \\
\text { than arthritis } \\
\text { Scoring Range (for each subscale): } 10-100 \text { with } 100 \text { indicating greatest } \\
\text { self-efficacy }\end{array}$ & $\begin{array}{l}\text { Coping and ability manage aspects of } \\
\text { disease }\end{array}$ \\
\hline PHQ-9 $[10,11]$ & $\begin{array}{l}\text { Patient Health Questionnaire } 9 \\
\text { Scoring Range: } 0-27 \text { with } 27 \text { indicating the most severe depression }\end{array}$ & Depression \\
\hline GAD-7 [12] & $\begin{array}{l}\text { Generalized Anxiety Disorder } 7 \\
\text { Scoring Range: } 0-21 \text { with } 21 \text { indicating the most severe anxiety }\end{array}$ & Anxiety \\
\hline PSS $[13,14]$ & $\begin{array}{l}\text { Perceived Stress Scale } \\
\text { Scoring Range: } 0-40 \text { with } 40 \text { indicating greatest stress }\end{array}$ & Stress \\
\hline MOS-SSS [15] & $\begin{array}{l}\text { Medical Outcomes Study Social Support Survey } \\
\text { Scoring Range: 0-100 with } 100 \text { indicating the high levels of perceived } \\
\text { social support }\end{array}$ & Social support \\
\hline MTHCSS [16] & $\begin{array}{l}\text { Multidimensional Trust in Health Care Systems Scale } \\
\text { Scoring Range: } 17-85 \text { with } 85 \text { indicating greatest trust in the } \\
\text { healthcare system }\end{array}$ & Trust \\
\hline Picker Survey & Modified 7-item scale & $\begin{array}{l}\text { Patient centered care- assesses patient's } \\
\text { experience with their physician }\end{array}$ \\
\hline MHLC $[17,18]$ & $\begin{array}{l}\text { Multidimensional Health Locus of Control } \\
\text { Scoring Range: } 18-90 \text { with } 90 \text { indicating greatest perceived control }\end{array}$ & $\begin{array}{l}\text { Measures patient's perceived control over } \\
\text { their health }\end{array}$ \\
\hline DSES $[19,20]$ & $\begin{array}{l}\text { Daily Spiritual Experience Scale } \\
\text { Scoring Range: } 6-36 \text { with } 36 \text { indicating lowest spirituality }\end{array}$ & Spirituality \\
\hline Distance Survey [21] & Diabetes Study of Northern California survey & Perceived discrimination \\
\hline
\end{tabular}

two clusters of patients, as determined by the PROs, are presented in Tables 2 and 3 [25-45]. Table 2 provides the differences in demographic characteristics between clusters and the Table 3 shows how the PROs separate by cluster, in terms of baseline levels, post-intervention values, and amount of change for each variable.

The majority of subjects in Cluster 1 were older than $45(\mathrm{~N}=11,55.0 \%)$, college educated $(\mathrm{N}=12,63.2 \%)$, and had an income of less than
35,000 ( $\mathrm{N}=10,66.7 \%$; $\mathrm{N}$ missing=5) Table 2.

In terms of the PROs, the primary (statistically significant) discriminators of the two clusters appear to be the baseline cumulative severity of symptoms (SLAQ 2) and disease activity rating (SLAQ 3). Mentees in Cluster 2 had significantly worse symptom severity $(\mathrm{p}=0.034)$ and disease activity $(p<0.001)$ at baseline than those in Cluster 1 . There was also a significant difference between clusters with regard to the changes in 


\begin{tabular}{|c|c|c|c|c|c|}
\hline \multicolumn{2}{|c|}{ Demographic } & $\begin{array}{c}\text { Total } \\
(\mathrm{N}=20)\end{array}$ & $\begin{array}{c}\text { Cluster } 1 \\
(\mathrm{~N}=12)\end{array}$ & $\begin{array}{c}\text { Cluster } 2 \\
(\mathrm{~N}=\mathbf{8})\end{array}$ & p \\
\hline \multirow{2}{*}{ Education } & No College & 7 (36.8\%) & $4(36.4 \%)$ & $3(37.5 \%)$ & \multirow{2}{*}{1.00} \\
\hline & College & 12 (63.2\%) & 7 (63.6\%) & $5(62.5 \%)$ & \\
\hline \multirow{2}{*}{ Age } & $<45$ & $9(45.5 \%)$ & $5(41.7 \%)$ & $4(50.0 \%)$ & \multirow{2}{*}{1.00} \\
\hline & $\geq 45$ & 11 (55.0\%) & $7(58.3 \%)$ & $4(50.0 \%)$ & \\
\hline \multirow{2}{*}{ Income } & $<35 \mathrm{k}$ & $10(66.7 \%)$ & $7(77.8 \%)$ & $3(50.0 \%)$ & \multirow{2}{*}{0.33} \\
\hline & $\geq 35 \mathrm{k}$ & $5(33.3 \%)$ & $2(22.2 \%)$ & $3(50.0 \%)$ & \\
\hline
\end{tabular}

SLAQ 3. Following the intervention, mentees in Cluster 2 reported significantly more change/ improvement in disease activity $(\mathrm{p}<0.001)$ than those in Cluster 1. No significant differences were detected at post-follow up for any of the PROs Table 3.

\section{Discussion}

The current study investigated the patient characteristics that predicted individual improvement in SLE patients following participation in a peer mentoring program [18]. Of all of the variables examined, only two disease activity variables were significantly associated with improvement. Those mentees with worse self-reported baseline symptom severity (SLAQ2) and disease activity ratings (SLAQ3) had the highest likelihood of improvement over time. In our primary findings [18], two measures (disease activity rating/SLAQ3 and anxiety/ GAD) showed significant change from baseline to follow-up, so it is not surprising that disease activity, with an effect size of near 0.80 , was the dominating measure to cluster participants in the current analysis; particularly since most of the other included measures' effect sizes were around 0.30 or less.

Interestingly, the second largest effect size in our primary results was seen in anxiety (GAD), but none of the comparisons for that measure were significant; whereas symptom severity (SLAQ2) showed separation within baseline values.

Furthermore, our cluster analysis on measure changes did not separate participants based on symptom severity (SLAQ2) change, but rather their baseline visit values. Despite there being a significant difference in baseline measures for symptom severity (SLAQ 2) and no significant difference in symptom severity (SLAQ 2) change, there was not a significant difference in post-intervention symptom severity (SLAQ 2) detected.

The finding of no significant difference in any of the measures for the post-intervention comparisons may be positive, as it indicates that all participants reached a common level of improvement following the peer mentoring intervention. Granted, this comes with the caveat that there may well be differences and we were just underpowered to detect them. It should be noted that the small sample size is a shortcoming in this analysis. Cluster analyses are more capable of detecting inter-cluster variation when larger sample sizes are utilized; however this was not feasible within the scope of the present pilot study $[46,47]$.

Nevertheless, the results of this study still do suggest a proof of concept and that there is a subset of SLE patients that could greatly benefit from such an intervention; namely patients with more severe disease to begin with may be more likely to benefit from the peer mentoring program. This is consistent with other studies that show chronic pain management interventions are more effective in patients with more severe disease forms and that chronic disease management programs are most effective in the severely ill patients or those with the most room to improve in relation to outcome measures [4850]. This should not, however, suggest that peer mentoring programs should not be offered to patients with milder disease. Rather, it may be efficient to more aggressively target those below a certain threshold of baseline disease activity or further research may indicate that baseline scores should drive the frequency and/or duration of interactions. For example, shorter and less frequent mentoring interactions may increase the effectiveness of the current training program among those patients with better baseline disease activity scores.

Overall, it is promising that all Cluster 2 mentees with poorer disease activity ratings (SLAQ 3) at baseline improved enough to be near-indistinguishable from Cluster 1 mentees who had better disease activity ratings (SLAQ 3) to begin with. Given the small sample size, our desired question of knowing characteristics 
Research Article Williams, Hyer, Viswanathan, et al.

\begin{tabular}{|c|c|c|c|c|}
\hline Patient Reported Outcome & Variable & $\begin{array}{c}\text { Cluster } 1 \\
N=12\end{array}$ & $\begin{array}{c}\text { Cluster } 2 \\
\mathbf{N}=\mathbf{8}\end{array}$ & $\mathbf{p}$ \\
\hline \multirow{3}{*}{ Cumulative Damage } & CHANGE & $0(-3,1)$ & $-2(-2.5,0)$ & 0.5 \\
\hline & $B L$ & $2(1,3.5)$ & $5(2.5,7)$ & 0.07 \\
\hline & POST & $2(1,3)$ & $3(1,9)$ & 0.38 \\
\hline \multirow{3}{*}{ SLAQ 1} & CHANGE & $0(-0.5,0)$ & $-1(-2,0)$ & 0.12 \\
\hline & $B L$ & $1(0,2)$ & $2(1,2.5)$ & 0.25 \\
\hline & POST & $1(0,2)$ & $1(0,1.5)$ & 0.97 \\
\hline \multirow{3}{*}{ SLAQ 2} & CHANGE & $0(-6,2)$ & $-6(-17,3.5)$ & 0.42 \\
\hline & $B L$ & $22.5(10.5,25)$ & $29.5(25,37)$ & 0.034 \\
\hline & POST & $12.5(6,25)$ & $20(6,32.5)$ & 0.56 \\
\hline \multirow{3}{*}{ SLAQ 3} & CHANGE & $0.5(-1.5,4.5)$ & $-54(-67,-47.5)$ & $<0.001$ \\
\hline & $\mathrm{BL}$ & $5(3.5,6)$ & $60(55,75)$ & $<0.001$ \\
\hline & POST & $6(4,7.5)$ & $7(6,8.5)$ & 0.22 \\
\hline \multirow{3}{*}{ Support } & CHANGE & $0.5(0,3)$ & $1(0,4)$ & 0.72 \\
\hline & $\mathrm{BL}$ & $12.5(9.5,16)$ & $12(8,16)$ & 0.72 \\
\hline & POST & $14(11.5,16)$ & $13(12,16)$ & 1 \\
\hline \multirow{3}{*}{ Health Literacy } & CHANGE & $0(0,1)$ & $0(-1.5,0.5)$ & 0.49 \\
\hline & $\mathrm{BL}$ & $10(8,11)$ & $9(7.5,11)$ & 0.47 \\
\hline & POST & $10(9,11)$ & $8.5(7,10.5)$ & 0.11 \\
\hline \multirow{3}{*}{ Stress } & CHANGE & $-1(-3,0)$ & $2.5(-1,3.5)$ & 0.1 \\
\hline & $\mathrm{BL}$ & $9(7.5,10)$ & $8(4.5,11)$ & 0.67 \\
\hline & POST & $8(5,10)$ & $10(9.5,10)$ & 0.06 \\
\hline \multirow{3}{*}{ Trust } & CHANGE & $-1(-3,0)$ & $-1(-5.5,3.5)$ & 0.93 \\
\hline & BL & $38.5(38,43.5)$ & $38(28,45)$ & 0.54 \\
\hline & POST & $38(36,40)$ & $38(31,43)$ & 0.84 \\
\hline \multirow{3}{*}{ Patient Engagement } & CHANGE & $0(-1,0)$ & $-1(-1,0)$ & 0.46 \\
\hline & $B L$ & $3(1.5,3.5)$ & $3(3,4)$ & 0.31 \\
\hline & POST & $2(1,3)$ & $2.5(2,3.5)$ & 0.28 \\
\hline \multirow{3}{*}{ Physician Engagement } & CHANGE & $0(-1,3)$ & $-0.5(-3,0)$ & 0.5 \\
\hline & BL & $8.5(7.5,11.5)$ & $13.5(7.5,19)$ & 0.16 \\
\hline & POST & $8(6,14)$ & $12(9,18)$ & 0.3 \\
\hline \multirow{3}{*}{ Control_Chance } & CHANGE & $0(-4,3)$ & $2.5(-2.5,9.5)$ & 0.51 \\
\hline & $\mathrm{BL}$ & $17.5(13.5,22.5)$ & $11.5(9.5,20)$ & 0.28 \\
\hline & POST & $18(14,20)$ & $19(12.5,21.5)$ & 0.62 \\
\hline \multirow{3}{*}{ Control_Doctors } & CHANGE & $1(-5,2)$ & $-2(-6,-0.5)$ & 0.07 \\
\hline & $B \mathrm{~L}$ & $14.5(12,16.5)$ & $14(11,16.5)$ & 0.91 \\
\hline & POST & $13(11,17)$ & $11(10,12.5)$ & 0.09 \\
\hline \multirow{3}{*}{ Cotrol_Internal } & CHANGE & $-1(-4,4)$ & $-0.5(-2,1.5)$ & 0.48 \\
\hline & $B \mathrm{~L}$ & $23(18,24.5)$ & $21.5(14,24.5)$ & 0.61 \\
\hline & POST & $20(18,22)$ & $21(16,23.5)$ & 0.8 \\
\hline \multirow{3}{*}{ Spirituality } & CHANGE & $-2(-6,1)$ & $-1(-8,0.5)$ & 1 \\
\hline & $\mathrm{BL}$ & $12(10.5,14)$ & $12(6.5,21)$ & 1 \\
\hline & POST & $7(6,12)$ & $11(6,15)$ & 0.7 \\
\hline \multirow{3}{*}{ Perceived Discrimination } & CHANGE & & & \\
\hline & $B L$ & $4.5(4,6)$ & $6(4,7)$ & 0.56 \\
\hline & POST & & & \\
\hline \multirow{3}{*}{ Depression } & CHANGE & $-2(-5.5,-1)$ & $-2.5(-4.5,3)$ & 0.85 \\
\hline & $B L$ & $7(3,11)$ & $7.5(3.5,12.5)$ & 0.82 \\
\hline & POST & $5(2.5,7)$ & $6.5(2,8)$ & 0.64 \\
\hline
\end{tabular}




\begin{tabular}{|c|c|c|c|c|}
\hline \multirow{3}{*}{ GAD } & CHANGE & $-3(-6,-1)$ & $-1(-3,0.5)$ & 0.14 \\
\hline & $\mathrm{BL}$ & $7(4,8.5)$ & $5.5(2.5,7)$ & 0.44 \\
\hline & POST & $2.5(1,5)$ & $4(1.5,6.5)$ & 0.53 \\
\hline \multirow{3}{*}{ SF36 SOCFUN } & CHANGE & $6.3(-12.5,18.8)$ & $12.5(-6.3,50)$ & 0.43 \\
\hline & $\mathrm{BL}$ & $62.5(37.5,62.5)$ & $31.3(6.3,68.8)$ & 0.29 \\
\hline & POST & $62.5(43.8,75)$ & $68.8(37.5,75)$ & 0.87 \\
\hline \multirow{3}{*}{ Coping } & CHANGE & $-10(-170,20)$ & $44.5(-20.5,104.5)$ & 0.32 \\
\hline & $\mathrm{BL}$ & $375(325,435)$ & $315(145.5,425)$ & 0.25 \\
\hline & POST & $350(230,470)$ & $305(210,434.5)$ & 0.97 \\
\hline \multirow{3}{*}{ Patient Dissatisfaction } & CHANGE & $0(-2,1)$ & $0(-1.5,0.5)$ & 0.67 \\
\hline & $\mathrm{BL}$ & $4(2.5,5)$ & $3.5(3,5)$ & 0.97 \\
\hline & POST & $4(2,5)$ & $3.5(3,4)$ & 0.73 \\
\hline \multirow{3}{*}{ Patient Satisfaction } & CHANGE & $0(0,1)$ & $0(-1,1)$ & 0.46 \\
\hline & $\mathrm{BL}$ & $2(1,2)$ & $2(1,3)$ & 0.31 \\
\hline & POST & $2(1,2)$ & $2(1,2)$ & 0.92 \\
\hline
\end{tabular}

associated with greater/ less improvement was not answerable. Rather, we observed separation based on who had more room for improvement and those who were already doing well. Those mentees who could improve, improved. That is, there wasn't a mix of participants who had more severe symptoms (SLAQ 2) and poorer disease activity ratings (SLAQ 3) to begin with (Cluster 2) that did not improve at all; Everyone (8 out of 8 ) in Cluster 2 improved and there was complete and total separation of disease activity (SLAQ 3) ratings at baseline.

This suggests the effectiveness of the peer mentoring approach in African American women with SLE with regard to symptom severity and disease activity, particularly for those with poorer baseline scores. However, future investigations will need to include larger sample sizes in order to formally investigate why within clusters, some mentees improved more than others. There is also the possibility of examining the relevance and impact of additional participant data that wasn't included in the current report. As all patients attended all sessions, "dose of therapy" was not a relevant predictor variable, but we did assess the duration of phone sessions and whether phone sessions were held as scheduled or were delayed. We also examined mentor assignment as a potential predictor, and while the majority of mentors had mentees that fell into both clusters, one mentor had all Cluster 1 mentees and another mentor had all Cluster 2 mentees. Further investigation could also determine finer details in non-SLAQ measures that had variable participant responses as well as whether adapted intervention characteristics may facilitate enhanced program effectiveness in participants with milder disease.

\section{Declarations}

\section{Consent for Publication}

All authors have read and approved the final version of this manuscript

\section{Availability of Data and Material}

Upon request to corresponding author

Competing Interests

None to declare

Funding

This work was supported by the South Carolina Clinical \& Translational Research (SCTR) Institute, with an academic home at the Medical University of South Carolina CTSA, National Institutes of Health/National Center for Advancing Translational Sciences Grant Number UL1; the Rheumatology and Immunology MCRC National Institutes of Health/National Institute of Arthritis and Musculoskeletal and Skin Diseases Grant Number AR062755; National Institutes of Health/ National Institute of Arthritis and Musculoskeletal and Skin Diseases K23 AR052364; and National Institutes of Health/National Center for Research Resources UL1 RR029882. The contents are solely the responsibility of the authors and do not necessarily represent the official views of the NIH, NIAMS, or NCATS. The funding sources had no input on study design; in the collection, analysis and interpretation of data; in the writing of the report; or in the decision to submit the article for publication. The authors have no conflicts of interest to declare.

\section{Authors' Contributions}

EMW, JO, and LE designed the study and together with TDF carried out the procedures. MH and RV performed the data analysis and all authors made critical contributions and revisions to the manuscript.

Acknowledgements

$\mathrm{N} / \mathrm{A}$ 


\section{References}

1. Campbell R Jr., Cooper GS, Gilkeson GS. Two aspects of the clinical and humanistic burden of systemic lupus erythematosus: mortality risk and quality of life early in the course of disease. Arthritis. Rheum. 59(4), 458-64 (2008).

2. Pons-Estel GJ, Alarcon GS, Scofield L et al. Understanding the epidemiology and progression of systemic lupus erythematosus. Semin. Arthritis. Rheum. 39(4), 257-68 (2010).

3. Fernández M, Alarcón GS, Calvo-Alén J et al. A multiethnic, multicenter cohort of patients with systemic lupus erythematosus (SLE) as a model for the study of ethnic disparities in SLE. Arthritis. Rheum. 57(4), 576-84 (2007).

4. Lau CS, Yin G, Mok MY. Ethnic and geographical differences in systemic lupus erythematosus: an overview. Lupus. 15(11), 715-9 (2006).

5. Gillis JZ, Yazdany J, Trupin L et al. Medicaid and access to care among persons with systemic lupus erythematosus. Arthritis. Care. Res. 57(4), 601-7 (2007).

6. Yazdany J, Gillis J, Trupin L et al. Association of socioeconomic and demographic factors with utilization of rheumatology subspecialty care in systemic lupus erythematosus. Arthritis. Rheum. 57, 593-600 (2007).

7. Ow M, Ho P, Thumboo J et al. Factors associated with health services utilization in patients with systemic lupus erythematosus: a systematic review. Clin. Exp. Rheumatol. 28, 892-904 (2010)

8. Alarcon G, Beasley T, Roseman J. Ethnic disparities in health and disease: the need to account for ancestral admixture when estimating the genetic contribution to both (LUMINA XXVI). Lupus. 14(10), 867-8 (2005).

9. Daleboudt G, Broadbent E, McQueen F et al. The impact of illness perceptions on sexual functioning in patients with systemic lupus erythematosus. 74(3), 260-4 (2013).

10. Danoff-Burg S, Friedberg F. Unmet Needs of Patients with Systemic Lupus Erythematosus. Behav. Med. 35(1), 5-13 (2009).

11. Jolly M. How does quality of life of patients with systemic lupus erythematosus compare with that of other common chronic illnesses? J. Rheumatol. 32(9), 1706-8 (2005).

12. Sehlo M, Bahlas S. Perceived illness stigma is associated with depression in female patients with systemic lupus erythematosus. J. Psychosom. Res. 74(3), 248-51 (2013).

13. Beckerman N. Living with lupus: a qualitative report. Soc Work Health Care. 50(4), 330-43 (2011).

14. Philip E, Lindner H, Lederman L. Relationship of illness perceptions with depression among individuals diagnosed with lupus. Depress. Anxiety. 26(6), 575-82 (2009).

15. Moses N, Wiggers J, Nicholas C et al. Prevalence and correlates of perceived unmet needs of people with systemic lupus erythematosus. Patient. Educ. Couns. 57(1), 30-8 (2005).

16. McElhone K, Abbott J, Teh LS. A review of health related quality of life in systemic lupus erythematosus. Lupus. 15, 633-43 (2006).
17. Macejová Z, Záriková M, Oetterová M. Systemic lupus erythematosus--disease impact on patients. Cent. Eur. J. Public. Health. 21(3), 171-3 (2013).

18. Williams E, Voronca D, Hyer M. Peer-to-peer mentoring for African American women with lupus: A feasibility pilot. Arthritis Care \& Research (In Press). (2017).

19. Greco C, Rudy T, Manzi S. Effects of a stress-education program on psychological function, pain, and physical function of systemic lupus erythematosus patients: A randomized controlled trial Arthritis \& Rheumatism. 51(4), 625-34 (2004).

20. Lorig K, Ritter P, Plant K. A disease-specific self-help program compared with a generalized chronic disease self-help program for arthritis patients. Arthritis \& Rheumatism. 53(6), 950-7 (2005).

21. Williams E, Kamen D, Penfield $M$ et al. Stress Intervention and Disease in African American Lupus Patients: The Balancing Lupus Experiences with Stress Strategies (BLESS) Study. Health. 6(1), 71-9 (2014).

22. Williams E, Penfield M, Kamen D et al. An Intervention to Reduce Psychosocial and Biological Indicators of Stress in African American Lupus Patients: The Balancing Lupus Experiences with Stress Strategies Study. Open. J. Prev. Med. 4(1), 22-31 (2014).

23. Sawilowsky S. New Effect Size Rule of Thumb. J. Mod. Appl. Stat. Methods. 8(2), 597-9 (2009).

24. Sullivan G, Feinn R. Using Effect Size- or Why the P Value is not Enough. J. Grad. Med. Educ. 4(3), 279-82 (2012).

25. Webster K, Cella D, Yost K. The Functional Assessment of Chronic Illness Therapy (FACIT) Measurement System: Properties, Application, and Interpretation. Health. Qual. Life. Outcomes. 1(79) (2003).

26. Toloza S, Jolly M, Alarcón G. Quality-of-Life Measurements in Multiethnic Patients with Systemic Lupus Erythematosus: Cross-Cultural Issues. Curr. Rheumatol. Rep. 12(4), 237-49 (2010).

27. Hibbard J, Stockard J, Mahoney E et al. Development of the Patient Activation Measure (PAM): conceptualizing and measuring activation in patients and consumers. Health. Serv. Res. 39(4 Pt 1), 1005-26 (2004).

28. Hibbard J, Mahoney E, Stockard J et al. Development and testing of a short form of the patient activation measure. Health. Serv. Res. 40(6), 1918-30 (2005).

29. Karlson E, Daltroy L, Rivest C et al. Validation of a systemic lupus activity questionnaire (SLAQ) for population studies. Lupus. 12, 280-6 (2003).

30. Borkovec T, Nau S. Credibility of analogue therapy rationales. J. Behav. Ther. Exp. Psy. 3(4), 257-60 (1972).

31. Baker D, Williams M, Parker R et al. Development of a brief test to measure functional health literacy. Patient. Educ. Couns. 38(1), 33-42 (1999).

32. Drenkard C, Yazdany J, Trupin L et al. Validity of a self-administered version of the brief index of lupus damage in a predominantly African American systemic lupus erythematosus cohort. Arthritis. Care. Res (Hoboken). 66(6), 888-96 (2014).

33. Lorig K, Chastain R, Ung E et al. Development and 
evaluation of a scale to measure perceived self-efficacy in people with arthritis. Arthritis \& Rheumatism. 32(1), 37-44 (1989).

34. Kroenke K, Spitzer R, Williams J. The PHQ-9. J. Gen. Intern. Med. 16(9), 606-13 (2001).

35. Kroenke K, Spitzer R. The PHQ-9: A new depression and diagnostic severity measure. Psychiatric. Annals. 32, 509-21 (2002).

36. Spitzer R, Kroenke K, Williams J et al. A brief measure for assessing generalized anxiety disorder: the GAD-7. Arch. Intern. Med. 166(10) (2006).

37. Cohen S, Williamson G. Perceived stress in a probability sample of the United States. In: Oskamp S, editor. The Social Psychology of Health. Newbury Park, CA; Sage. (1988)

38. Cohen S, Kamarck T, Mermelstein R. A global measure of perceived stress. J. Health. Soc. Behav. 24, 385-96 (1983).

39. Sherbourne C, Stewart A. The MOS social support survey. Soc. Sci. Med. 32, 705-14 (2008).

40. Egede L, Ellis C. Development and testing of the Multidimensional Trust in Health Care Systems Scale. J. Gen. Intern. Med. 23(6), 808-15 (2008).

41. Wallston K, Wallston B, DeVellis R. Development of the Multidimensional Health Locus of Control (MHLC) Scales. Health. Educ. Monogr. 6, 160-70 (1978).

42. Kazis L, Miller D, Skinner K et al. Patient reported measures of health: The Veterans Health Study. J. Ambul. Care. Manage. 70-83 (2004).
43. Underwood L, Teresi J. The daily spiritual experience scale: development, theoretical description, reliability, exploratory factor analysis, and preliminary construct validity using healthrelated data. Ann. Behav. Med. 24, 22-33 (2002).

44. Loustalot F, Wyatt S, Boss B et al. Psychometric examination of the Daily Spiritual Experiences Scale. J. Cult. Divers. 13, 162-7 (2006)

45. Moffet H, Adler N, Schillinger D et al. Cohort Profile: Diabetes Study of North California (DISTANCE) objectives and design of a survey follow-up study of social health disparities in a managed care population. Int. J. Epidemiol. 38(1), 38-47 (2009).

46. Campbell M, Thomson S, Ramsay C et al. Sample size calculator for cluster randomized trials. Comput. Biol. Med. 34(2), 113-25 (2004).

47. Fosgate G. A cluster-adjusted sample size algorithm for proportions was developed using a beta-binomial model. J. Clinical Epidemiology. 60(3), 250-5 (2007).

48. Scascighini L, Toma V, Dober-Spielmann S et al. Multidisciplinary treatment for chronic pain: a systematic review of interventions and outcomes. Rheumatology. 47(5), 670-8 (2008).

49. Coultas D, Jackson B, Russo R et al. A Lifestyle Physical Activity Intervention for Patients with Chronic Obstructive Pulmonary Disease. A Randomized Controlled Trial. Annal of the American Thoracic Society. 13(5), 617-26 (2016).

50. Krause D. Economic Effetiveness of Disease Management Programs: A Meta-Analysis. Disease Management. 8(2), 114-34 (2005). 